\title{
Sistem Pendukung Keputusan Seleksi Bantuan Operasional Madrasah Menggunakan Metode Weighted Aggregatedsum Product Assessment Berbasis Android Pada Kementerian Agama Kabupaten Pohuwato
}

\author{
M. Salim1, Sulistiawati R.N.Ahmad 2, \\ 13 STMIK Ichsan Gorontalo 2 Universitas Ichsan Gorontalo \\ Lantai 2, Kampus $1 \mathrm{Jl}$. Ahmad Nadjamudin \\ e-mail:.mohsalim87@yahoo.com,2 sulistiawatiahmad@gmail.com
}

\begin{abstract}
The Government has a responsibility to educate every one of its people and has become its duty to develop every potential of its people, especially among school ages, to become human beings who believe and fear the Almighty God, Noble, healthy, knowledgeable, capable, creative, independent. In the field of religious education in this case the Islamic religion through Islamic educational institutions conducted in Madrasah has made a great contribution to the development of the nation. Through the madrasah, it is able to give birth to generations of Islamic characters and national knowledge. With the advancement of technology, every decision can be taken quickly and accurately through a decision support system. The problem found in research was the selection of the Madrasah operational assistance, with a budget that has limited funds, election or screening is done as possible by checking one by one file and requiring time Older, file buildup allows some missing files to be misplaced. The method used is a descriptive method and the results of the study concluded that with the decision support system helped the Ministry of Religion Pohuwato to distribute operational assistance in the madrasas evenly.
\end{abstract}

Keyword : Decision Support System, help, android

Abstrak - Pemerintah mempunyai tanggung jawab untuk mencerdaskan setiap rakyatnya dan telah menjadi tugasnya untuk mengembangkan setiap potensi rakyatnya terutama kalangan usia sekolah untuk menjadi manusia yang beriman dan bertakwa kepada Tuhan Yang Maha Esa, berakhlak mulia, sehat, berilmu, cakap, kreatif, mandiri. Dalam bidang pendidikan keagamaan dalam hal ini agama islam melalui lembaga pendidikan islam dilakukan di Madrasah telah memberikan kontribusi besar terhadap pembangunan bangsa. Melalui madrasah mampu melahirkan generasi bangsa berkarakter Islami dan berwawasan kebangsaan. Dengan kemajuan teknologi yang ada setiap keputusan dapat diambil secara cepat dan akurat melalui sistem pendukung keputusan. Masalah yang ditemukan dilokasi penelitian adalah penyeleksian bantuan operasional madrasah, dengan anggaran yang dana yang terbatas, pemilihan atau penyeleksian dilakukan seteliti mungkin dengan memeriksa satu persatu berkas dan membutuhkan waktu yang lama, penumpukan berkas memungkinkan ada beberapa berkas hilang tercecer. Metode yang digunakan adalah metode deskriptif dan hasil penelitian menyimpulkan bahwa dengan adanya system pendukung keputusan membantu Kementerian Agama Pohuwato untuk menyalurkan bantuan operasional pada madrasah-madrasah secara merata.

Kata kunci : Sistem pendukung keputusan, Bantuan, android

\section{Pendahuluan}

Pemerintah mempunyai tanggung jawab untuk mencerdaskan setiap rakyatnya, telah menjadi tugas pemerintah untuk mengembangkan setiap potensi rakyatnya terutama kalangan usia sekolah untuk menjadi manusia yang beriman dan bertakwa kepada Tuhan Yang Maha Esa, berakhlak mulia, sehat, berilmu, cakap, kreatif, mandiri. Dalam bidang pendidikan keagamaan dalam hal ini agama islam melalui lembaga pendidikan islam dilakukan di Madrasah telah memberikan kontribusi besar terhadap pembangunan bangsa. Melalui madrasah mampu melahirkan generasi bangsa berkarakter Islami dan berwawasan kebangsaan. Madrasah terbagi atas Madrasah Ibtidaiyah untuk pendidikan setingkat sekolah dasar, Madrasah Tsanawiyah untuk pendidikan setingkat sekolah menengah pertama dan Madrasah Aliyah untuk pendidikan setingkat sekolah menengah atas.

Perkembangan arus globalisasi dewasa ini yang semakin pesat berimbas salah satu diantaranya 
adalah perkembangan dalam bidang komputer yang merupakan produk dari ilmu pengetahuan dan teknologi yang setiap saat berkembang dengan pesat dan cepat. Sebagian besar aktivitas telah menggunakan jasa komputer sebagai alat bantu dan dari segi kegunaannya komputer dapat memberikan informasi yang sangat cepat, tepat dan akurat kepihak-pihak yang membutuhkan, namun dalam banyak kasus informasi tersebut masih kurang memadai untuk membuat keputusan yang spesifik guna memecahkan permasalahan yang spesifik, hal itu terjadi karena prosedur pengolahan datanya kurang dikembangkan. Oleh karena itu, dibutuhkan sistem pendukung keputusan yang memuat prosedur-prosedur pengolahan yang dapat mendukung dalam penemuan alternatif - alternatif keputusan.

Kementerian Agama Kabupaten Pohuwato merupakan salah satu lembaga yang berada dibawah kementerian Agama Republik Indonesia, dimana Salah satu tugas utamanya adalah mengelola lembaga pendidikan islam, untuk melaksanakan tugas pengelolaan tersebut, Kementerian Agama Kabupaten Pohuwato melakukan salah satunya adalah memberikan bantuan pendanaan untuk peningkatan madrasah atau disebut dengan bantuan operasional madrasah. Berikut ini adalah data madrasah tahun 2017 :

Tabel 1 Data Madrasah Tahun 2017

\begin{tabular}{|c|l|c|c|}
\hline No & Madrasah & Negeri & Swasta \\
\hline 1. & Madrasah Ibtidaiyah & 1 & 13 \\
\hline 2. & Madrasah Tsanawiyah & 2 & 10 \\
\hline 3. & Madrasah Aliyah & 1 & 7 \\
\hline
\end{tabular}

Sumber kementerian Agama Pohuwato

Pada Observasi awal yang dilakukan, ditemukan adanya masalah dalam penyaluran bantuan operasional pada kantor kementerian agama pohuwato terbatas, dari tabel 1. Dapat dilihat bahwa jumlah madrasah yang ada dikabupaten pohuwato sebanyak 24 sekolah. Anggaran dana yang terbatas membuat seleksi yang dilakukan memakan waktu karena penyeleksian dilakukan oleh Manusia (human) . seluruh sekolah berlomba - lomba memasukkan berkas, panitia seleksi berkas harus memeriksa satu persatu berkas sehingga tidak efisien dari segi waktu, penumpukan berkas memungkinkan ada beberapa berkas hilang tercecer dimasa pemeriksaan lalu hasil seleksi yang kurang memuaskan. masih belum tercapainya standar penilaian kelayakan agar dapat dan wajib menerima bantuan operasional sekolah tersebut, adanya subjektifitas akibat faktor kedekatan dengan oknum dengan pihak internal Sekolah. Masalah lainya adalah hasil pengumuman seleksi yang hanya ditempelkan dalam bentuk kertas pada papan pengumuman dan pemberian informasi lainnya lewat surat ke sekolah membuat bantuan operasional terlambat diketahui oleh pihak sekolah. Oleh karena itu dirancanglah suatu aplikasi sistem pendukung keputusan seleksi bantuan operasional madrasah yang mempermudah dan menyingkat waktu serta transparan. Dimana siswa dapat melihat pengumumnya secara langsung lewat smartphone, selain itu pula adanya penambahan fitur daftar nilai membuat siswa dan guru dapat memantau nilai serta memudahkan untuk membuat rekapan data nilai siswa yang merupakan salah satu syarat pengajuan bantuan operasional sekolah pada kementerian agama Pohuwato.

\section{STUDI LITERATUR}

Sistem Pendukung Keputusan mempunyai beberapa karakteristik yang membedakannya dengan sistem lain. Beberapa karakteristik dari Sistem Pendukung Keputusan adalah sebagai berikut:

a. Sistem Pendukung Keputusan menyediakan dukungan untuk pengambilan keputusan dalam area semi terstuktur dan tidak terstruktur dengan membawa penilaian pengguna secara bersamasama dengan informasi yang terkomputerisasi.

b. Sistem Pendukung Keputusan mendukung dengan cara menyediakan level-level manajerial, dari top eksekutif sampai ke level manajer.

c. Sistem Pendukung Keputusan mendukung semua fase dari proses pengambilan keputusan yaitu inteligensia, desain, pemilihan maupun penerapannya.

d. Sistem Pendukung Keputusan menyediakan dukungan untuk beberapa keputusan yang saling berhubungan.

e. Sistem Pendukung Keputusan mendukung variasi dari proses pengambilan keputusan dan cara yang digunakan.

f. Sistem Pendukung Keputusan beradaptasi terhadap waktu

g. Mudah digunakan, pengguna sistem harus merasa nyaman pada saat beinteraksi dengan sistem.

h. Lebih banyak digunakan untuk meningkatkan efektifitas pembuatan keputusan; akurasi, hemat waktu, kualitas dibandingkan dengan efisiensi 
biaya yang dibutuhkan untuk pengambilan keputusan.

i. Pengambil keputusan dapat mengontrol setiap tahapan proses pengambilan keputusan dalam pemecahan persoalan. Sistem Pendukung Keputusan diarahkan untuk mendukung keputusan dan bukan untuk menggantikan pembuat keputusan.

j. Memungkinkan pengguna akhir untuk membangun sendiri dan memodifikasi sistem yang sederhana

k. Sistem Pendukung Keputusan menggunakan model yang dimanfaatkan untuk analisis situasi pengambilan keputusan. Kemampuan modelnya dapat melakukan eksperimen dalam berbagai strategi yang berbeda pada konfigurasi yang berbeda pula.

Sistem Pendukung Keputusan dapat mengakses berbagai sumber data, format, maupun tipe sampai pada sistem yang berorientasi pada objek. Dengan berbagai karakteristik tersebut, Sistem Pendukung Keputusan dapat memberikan manfaat atau keuntungan bagi pemakainya

\section{METODE PENELITIAN}

\section{A. Metode Penelitian}

Penelitian ini menggunakan metode penelitian deskriptif. Penelitian deskriptif adalah metode penelitian yang digunakan untuk menemukan pengetahuan yang seluas - luasnya terhadap objek penelitian pada suatu masa tertentu. Metode penelitian ini penulis gunakan untuk dapat membangun sistem berdasarkan variabel-variabel angka-angka maupun kata-kata sehingga dapat menggambarkan dan menginterpretasi kebutuhan pengguna dari sistem yaitu Kementerian Agama Kabupaten Pohuwato.

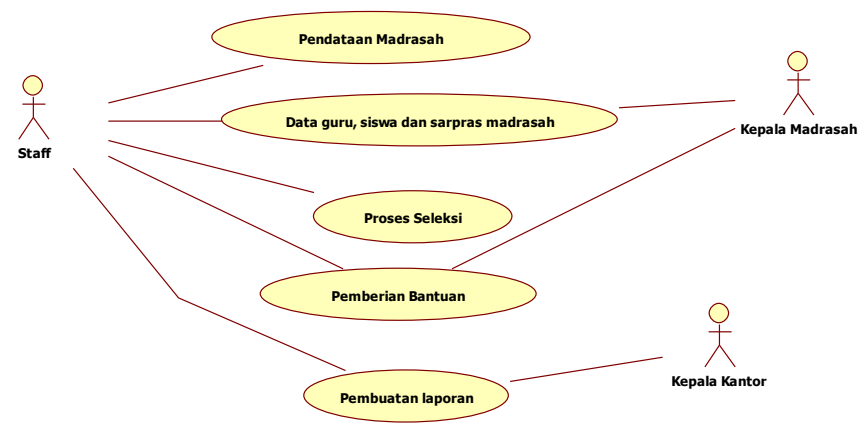

Gambar 1. Rancangan Sistem
Pada rancangan sistem ada 3 aktor yang berperan yaitu staf, kepala madrasah dan kepala kantor. Pada sistem yang berjalan aktor staf melakukan pendataan madrasah dan pendataan guru, siswa dan sarpras madrasah yang berasal dari kepala madrasah, selanjutnya proses seleksi, dan pemberian bantuan ke kepala madrasah, sedangkan Aktor kepala kantor menerima laporan dari staf.

Jenis dan Sumber Data

1. Data primer

Penulis melakukan observasi langsung ke lokasi penelitian dan melakukan pengumpulan data. Adapun data-data tersebut adalah berupa data madrasah tahun 2017.

2. Data Sekunder,

Untuk menambah data, penulis memperoleh dari sumber lain yaitu dokumentasi, jurnal, literatur, buku dan informasi lainnya yang berhubungan dengan penelitian.

Analisa Sistem yang Diusulkan

Dari sistem yang berjalan di atas sebenarnya tidak terlalu berbeda dengan sistem yang diusulkan. Aktor pada sistem yang diusulkan masih tetap sama dengan sistem yang sedang berjalan. sistem yang diusulkan berusaha untuk mengatasi permasalahan yang ditemui pada sistem yang sedang berjalan khususnya untuk memberikan informasi lebih kepada sekolah. Pemilihan system operasi android didasarkan pada banyaknya siswa yang menggunakan smartphone berbasis android disbanding system operasi lainnya sehingga menjadi pertimbangan sebagai platform aplikasi.

Tahap Desain

Adapun tahap pertama dari desain sistem yaitu arsitektur dan pemodelan aplikasi, dimana pada tahap ini penulis membuat pertimbanganpertimbangan tentang bagaimana suatu sistem akan diterapkan, baik dalam teknologi dan lingkungan implementasi. Pada tahap ini digunakan Unified Modelling Language(UML) untuk memodelkan persyaratan bisnis logis dari suatu sistem informasi. Selanjutnya dilakukan tahap desain database, dimana semua proses membuat, membaca, memperbaharui, dan menghapus (create, read, update, delete) data. Data disimpan dalam file dan database. Termasuk dalam tahap ini adalah pemodelan field kunci, record table, relasi database, entitas data. kemudian masuk pada tahap desain dan prototyping input dan output serta antar muka 
sistem, menggambarkan masukan dan keluaran bagi pengguna sistem, baik dalam bentuk formulir masukan, sistem organisasi menu, bentuk cetakan kertas ataupun tampilan ke layar monitor. Implementasi input merupakan masukan input dari keyboard dan mouse, penyesuaian tipe pengguna sistem, penggunaan gambar dan simbol (icon).

\section{Tahap Pengujian}

Melakukan pengetesan terhadap sistem yang telah selesai dibuat sebelum diimplementasikan dengan menggunakan teknik pengujian perangkat lunak yang telah ada yakni menggunakan pengujian White Box dan Black Box Testing. Setelah didapat hasil layak maka aplikasi dapat diimplementasikan ke kementerian Agama Pohuwato

Tahap Implementasi

Tahap implementasi sistem yaitu tahap meletakkan sistem agar siap untuk dioperasikan. Penerapan sistem ini yaitu pada Kementerian Agama Kabupaten Pohuwato dengan admin aplikasi ini Adalah staf administrasi dikantor kemenag, dan usernya adalah semua sekolah yang mengajukan bantuan operasional madrasah. Usernya akan diberikan pada setiap sekolah yang mendaftar pengajuan bantuan operasional madrasah.

\section{HASIL DAN PEMBAHASAN}

1. Hasil Pembahasan

Tampilan android untuk user Guru dan Siswa

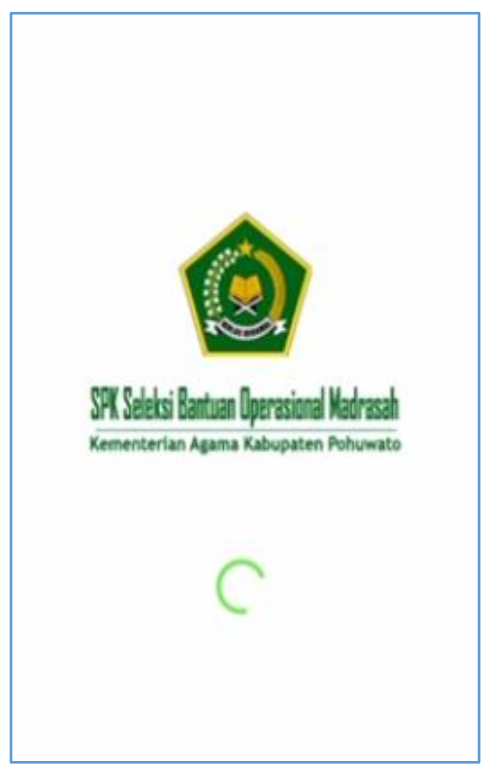

Gambar 2 Tampilan Login
Pada tampilan diatas merupakan tampilan awal saat login ke aplikasi sistem pendukung keputusan seleksi bantuan operasional madrasah.

\section{Tampilan Menu Utama}

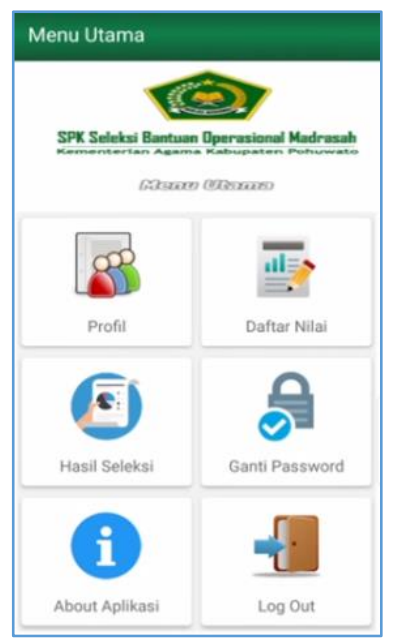

Gambar 3 Menu Utama

Pada Tampilan Menu Utama menyediakan fitur profil, daftar nilai, hasil seleksi, ganti password, about aplikasi dan logout

Tampilan menu utama seperti ini akan tampil dilayar smartphone user saat login, pengguna bisa mengganti password sesuai dengan keinginannya lewat menu Ganti Password, pada tampilan menu terdapat beberapa pilihan dengan fungsinya masingmasing yaitu :

1. Profil : isi profil yaitu informasi mengenai sekolah secara singkat, biodata guru dan siswa

2. Daftar nilai : pada fitur ini berbeda fungsi sesuai dengan autentikasi login yang ada. Login guru maka tampilan daftar nilai berisi data nilai matapelajaran dari mata pelajaran yang diampuh oleh masing-masing guru matapelajaran, pada menu ini guru menginput nilai siswa. Siswa login untuk dapat mengetahui nilai mereka. Nilai ini adalah prasayarat berkas sekolah mendapatkan bantuan operasional sekolah.

3. Hasil seleksi : siswa dapat melihat hasil seleksi daftar nama yang mendapatkan bantuan lewat aplikasi android. Dengan catatan siswa dapat melihat hasil apabila sudah menguplod berkas dan melengkapi persyaratan administrasi pada saat masa pendaftaran seleksi bantuan madrasah telah dibuka lewat seleksi sekolah. Oleh guru berkas siswa diseleksi lagi lewat aplikasi sistem pendukung keputusan bantuan madrasah dan 
mengirimkan daftar nama siswa yang telah lolos seleksi sekolah ke kantor kementarian Agama.

4. Ganti password : User bisa mengganti password default yang diberikan admin agar lebih mudah diingat.

5. About : berisi tentang informasi singkat pengembang aplikasi.

6. Logout : user bisa keluar dari aplikasi ini melalui menu ini.

\section{KESIMPULAN DAN SARAN}

\section{Kesimpulan}

Dari hasil penelitian di atas maka ditemukan beberapa hal sebagai kesimpulan, yaitu:

1. Sistem Pendukung Keputusan Seleksi Bantuan Operasional Madrasah menggunakan Metode Weighted Aggregated Sum Product Assessment Berbasis Android dapat menyeleksi dengan efisien tanpa memandang subjetifitas antara pihak sekolah dan panitia seleksi serta memangkas biaya operasional kantor kementerian dalam pengadaan kertas dan pencetakan surat.

2. Sistem ini dapat mempermudah madrasah untuk melihat hasil seleksi pengujian dengan menggunakan test case membuktikan bahwa Sistem Pendukung Keputusan Seleksi Bantuan Operasional Madrasah menggunakan Metode Weighted Aggregated Sum Product Assessment Berbasis Android lebih efektif dan efisien

\section{Saran}

Penelitian ini adalah penelitian awal yang dilakukan pada kantor Kementerian Pohuwato, masih banyak ditemui debug / eror sehingga perlu perbaikan dan penelitian lebih lanjut. Sehingga disarankan pada peneliti selanjutnya untuk menambahkan fitur lainnya yang mempermudah user dan admin berkomunikasi misalnya fitur chat. Metode yang digunakan bisa menggunakan metode waterfall, TOPSIS, PROMETHEE dan lain-lain.

\section{DAFTAR PUSTAKA}

[1] K. A. K. Pohuwato, "Profil Kemenag Pohuwato," Kementerian Agama Kabupaten Pohuwato, Kabupaten Pohuwato, 2018.

[2] E. D. Marbun, L. A. Sinaga, E. R. Simanjuntak, D. Siregar and J. Afriany, "Penerapan Metode Weighted Aggregated Sum Product Assessment Dalam Menentukan
Tepung Terbaik Untuk Memproduksi Bihun," Jurnal Riset Komputer (JURIKOM), vol. 5, no. ISSN 2407-389X, 2018.

[3] R. Manurung, Fitriani, R. Sitanggang, F. T. Waruwu and Fadlina, "Penerapan Metode Weighted Aggregated Sum Product Assessment Dalam Penentuan Penerima Beasiswa Bidik Misi," Jurnal Riset Komputer (JURIKOM), vol. 5, no. ISSN 2407-389X, 2018.

[4] S. Y. Hutagalung, F. Pratiwi and I. Wijaya, "Penerapan Metode Weighted Aggregated Sum Product Assesment (WASPAS) Dalam Keputusan Penerimaan Beasiswa," in Seminar Nasional Sains \& Teknologi Informasi (SENSASI) 2018, Medan, 2018.

[5] F. Ginting, Y. Angelita and A. . A. B. Ginting, "Sistem Pendukung Keputusan Menentukan Jumlah Produksi Menggunakan Metode Weighted Aggregated Sum Product Assessment (WASPAS)," in Seminar Nasional Sains \& Teknologi Informasi (SENSASI), 2018.

[6] B. R, Analytical Hierarchy Process: an Overview, Bogor: UNCAPSA-UNESCAP, 2011.

[7] BERLILANA, Berlilana; PRAYOGA, Fandhi Dhuga; UTOMO, Fandy Setyo. Implementasi Simple Additive Weighting dan Weighted Product pada Sistem Pendukung Keputusan untuk Rekomendasi Penerima Beras Sejahtera. Jurnal Teknologi Informasi dan Ilmu Komputer, [S.1.], v. 5, n. 4, p. 419426, okt. 2018. ISSN 2528-6579.

[8] Turban, A. Efraim, J. E and L. Ting Peng, Decision Support Sistem and Intelegence Sistems. 7th Edition, jilid 1, Jogyakarta: Penerbit ANDI, 2005.

[9] S. Y, Semua Bisa Menjadi Program Android, Jakarta: PT. Elex Media Komputindo, 2014.

[10] R. Hakim and Sutarto, Mastering Java : Konsep Pemrograman Java dan Penerapannya untuk membuat Software Aplikasi, Jakarta: PT. Elex Media Komputindo, 2010.

[11] Android Developer, "Android Studio Overview," 8 Oktober 2015. [Online]. Available:

http://developer.android.com/tools/studio/ind ex.html. 
[12] RAHAYU, Sarwati et al. Metode EntropySAW dan Metode Entropy-WASPAS dalam Menentukan Promosi Jabatan Bagi Karyawan Terbaik di Cudo Communications. Jurnal Teknologi Informasi dan Ilmu Komputer, [S.1.], peb. 2020. ISSN 2528-6579. 